\title{
Retroperitoneal pelvic invasion in ovarian cancer: Possible modes of spread
}

\section{and survival impact}

\author{
Stanislav Slavchev ${ }^{1}$, Angel Yordanov ${ }^{2}$
}

1. Clinic of Gynaecology, University Hospital "St. Anna"-Varna, Bulgaria

2. Department of Gynecologic Oncology, Medical University Pleven, Bulgaria

\section{RESEARCH}

Please cite this paper as: Slavchev S, Yordanov A. Retroperitoneal pelvic invasion in ovarian cancer: Possible modes of spread and survival impact. AMJ 2019;12(1):1114. https://doi.org/10.21767/AMJ.2018.3510

\section{Corresponding Author:}

Angel Danchev Yordanov

Clinic of Gynecologic Oncology, University Hospital "Dr. Georgi Stranski"-Pleven, Georgi Kochev 8A, Bulgaria Email: angel.jordanov@gmail.com

\section{ABSTRACT}

\section{Background}

Ovarian cancer is the second-most common malignancy and the leading cause of death in women who develop cancers of gynaecologic origin and it spread primarily by direct exfoliation of cells along the peritoneal surface. Interesting fact, although not well studied, is that these tumours invade the mesothelium but very rarely they invade the peritoneum deeper through direct extension.

\section{Aims}

To study the retroperitoneal pelvic invasion in parametrial ligaments and vagina in patients undergoing surgery for advanced epithelial ovarian carcinoma and the survival impact of it.

\section{Methods}

The study included 59 patients with advanced epithelial ovarian cancer that underwent radical hysterectomy during the 2004-2009 period. For the purpose of this study histopathologic examination was performed for the parametrial ligaments and vagina with inspection of the surgical resection lines.

\section{Results}

Retroperitoneal pelvic invasion was found in 42.4 per cent of the cases, involving different depths of parametrial ligaments and/or vaginal spread, and is associated to worse survival outcomes.

\section{Conclusion}

Retroperitoneal pelvic invasion is not a rare phenomenon and seems to be a feature of the more aggressive tumours. In the cases of distal retroperitoneal pelvic invasion (vaginal) the patients' 5-year survival rate is similar to that of the stage IV ovarian cancer patients.

\section{Key Words}

Ovarian cancer, retroperitoneal pelvic invasion, direct extension

\section{What this study adds:}

\section{What is known about this subject?}

Ovarian cancer is spread primarily by direct exfoliation of cells along the peritoneal surface.

\section{What new information is offered in this study?}

Retroperitoneal pelvic invasion, involving different depths of parametrial ligaments and/or vaginal spread is more often than it is thought.

3. What are the implications for research, policy, or practice?

This necessitates more aggressive surgical treatment in the early stages of ovarian cancer.

\section{Background}

Ovarian cancer is the second-most common malignancy and the leading cause of death in women with gynaecological cancers. $^{1,2}$ The most common ovarian cancer is the epithelial subtype, constituting 90 per cent of all ovarian neoplasms. ${ }^{3}$ Seventy percent of the patients present in advanced stages of the disease, with 10 -year survival rates 
around 15-30 per cent; in contrast - survival rates for earlier stages exceed 90 per cent. ${ }^{4-7}$ The reasons for the poor prognosis of epithelial ovarian cancer are the late diagnosis (in an advanced stage), the lack of effective screening, as well as the development of chemotherapyresistant recurrences.

\section{Method}

For the period from 2004-2009 in the Clinic of gynaecology 78 patients with advanced epithelial ovarian cancer were diagnosed and surgically treated. 59 of them underwent primary cytoreductive surgery with radical hysterectomy with a retroperitoneal approach and examination of the parametria and vagina for ovarian cancer metastases (Figures 1 and 2). The remaining 19 underwent total abdominal hysterectomy with bilateral adnexectomy and omentectomy. There was no differences of the treatment protocol between parametrium/vaginal invasion (+) vs. (-) groups. No neoadjuvant chemotherapy was done. The adjuvant chemotherapy was performed with carboplatin and paclitaxel given every three week. The study data were processed with the software packages SPSS 19.0, 19.0A. Descriptive statistics analysis methods were applied for the determination of mean values, standard deviations and median values. Survival curves were built applying the Kaplan-Meyer method and differences were analysed using the log-rank test. Statistical significance was defined as $p<0.05$.

Figure 1: Parametrial soft tissue infiltration by poorly differentiated serous adenocarcinoma (HGSC) of the ovary; muscle and fibrous tissue fibres (stained in yellow and red, respectively) with atypical glandular tumour structures and scattered clusters of tumour cells appearing inbetween them; Van Gieson staining, magnification x100

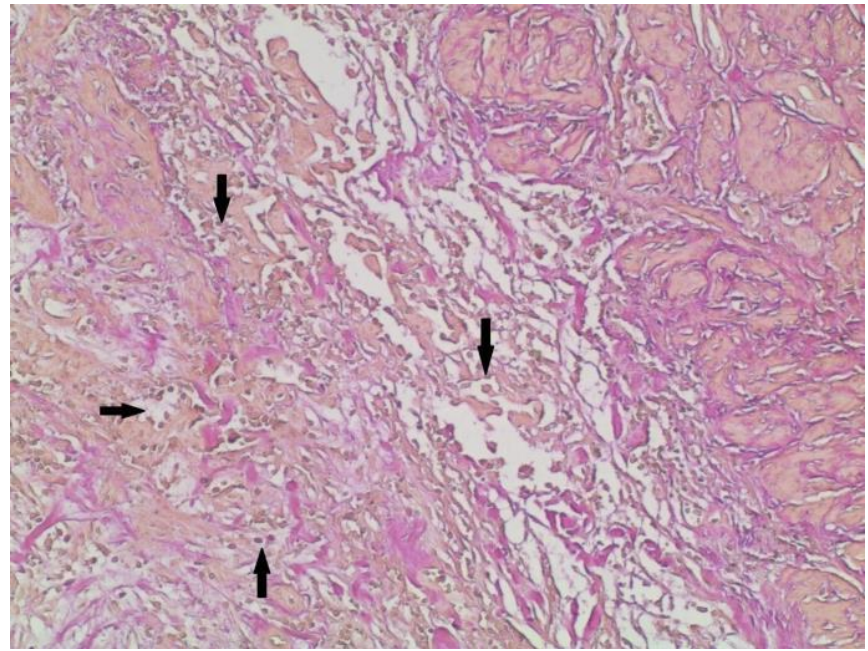

Figure 2: Part of vaginal wall / up, right - marked with thick arrow strip of preserved stratified squamous epithelium, on the left - fragments from invading tumour formation/; HE staining; magnification $\times 40$

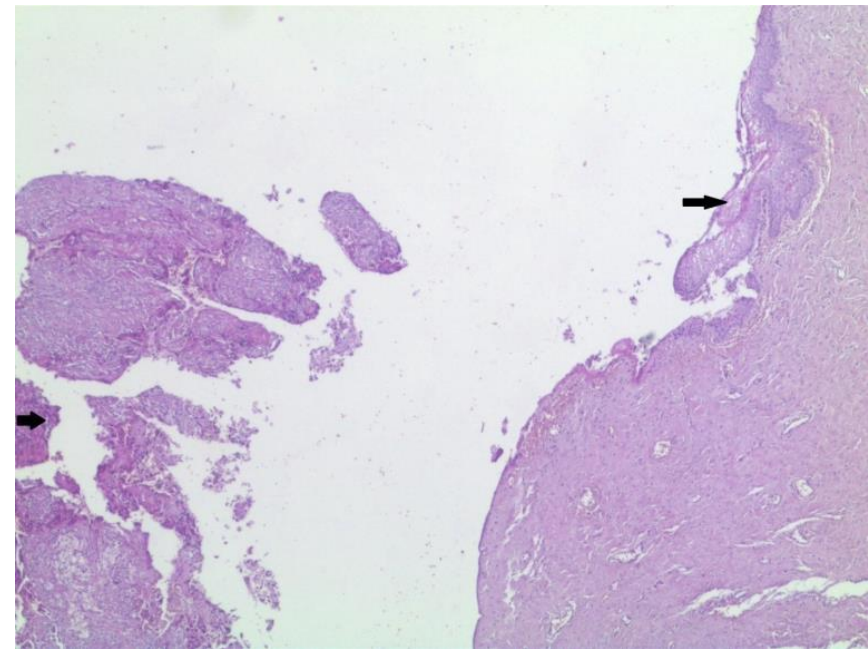

\section{Results}

Analysis of surgical protocols and histopathological reports showed retroperitoneal pelvic invasion (RPI) not related to pelvic lymph nodes in 25 patients out of 59 (42.4 per cent):

- 11 patients had proximal parametrial invasion;

- 3 patients - parametrial invasion + hydronephrosis;

- 1 patient - parametrial invasion to pelvic wall;

- In 10 patients (16.9 per cent) parametrial and vaginal invasion was found.

The patients were divided into three groups based on the level (depth) of retroperitoneal pelvic invasion: patients without RPI, patients with only parametrial involvement and third group - with parametrial and vaginal invasion. Overall survival (OS) was evaluated and compared between the groups applying the Kaplan-Meier, Log-Rank, Breslow, and Tarone-Ware methods (Figure 3 and Table 1). We found significant differences in the overall survival between the group with distal invasion in parameters and vagina and the group without RPI. Such significant difference is not observed between the groups without RPI and with only proximal involvement - of only parametria. Evaluating the 5-year survival we can see that there were no surviving patients with distal disease dissemination to the pelvic wall, as well as to the vagina (Table 2). The mean overall survival was 22 months, not depending on the residual tumour size. 
Figure 3: Kaplan-Meier survival curves for the three groups of patients: without RPI, with only parametrial involvement, with parametrial and vaginal invasion

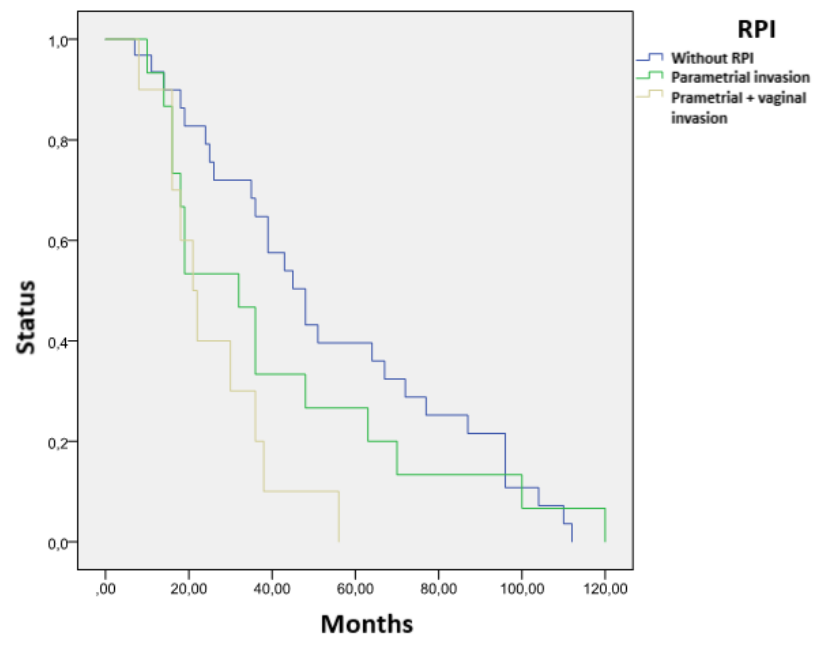

* retroperitoneal pelvic invasion

Table 1: Survival analysis

\begin{tabular}{|l|l|l|l|}
\hline & Chi-Square & $\mathrm{df}$ & Sig. \\
\hline $\begin{array}{l}\text { Log-Rank } \\
\text { (Mantel-Cox) }\end{array}$ & 7.927 & 2 & .019 \\
\hline $\begin{array}{l}\text { Breslow } \\
\text { (Generalized } \\
\text { Wilcoxon) }\end{array}$ & 7.359 & 2 & .025 \\
\hline Tarone-Ware & 7.839 & 2 & .020 \\
\hline
\end{tabular}

Table 2: RPI and 5-year survival analysis, by FIGO stage

\begin{tabular}{|l|l|l|l|}
\hline & Total & \multicolumn{2}{l|}{ FIGO stage } \\
\cline { 3 - 4 } & & IIIC & IV \\
\hline $\begin{array}{l}\text { Retroperitoneal } \\
\text { pelvic invasion } \\
\mathrm{N}=25\end{array}$ & $\begin{array}{l}5 \text { years OS } \\
(\%)\end{array}$ & $\begin{array}{l}5 \text { years OS } \\
(\%)\end{array}$ & $\begin{array}{l}5 \text { years OS } \\
(\%)\end{array}$ \\
\hline $\begin{array}{l}\text { Proximal } \\
\text { parametrial } \\
\text { invasion (N=11) }\end{array}$ & $4 / 1136 \%$ & $4 / 1136 \%$ & - \\
\hline $\begin{array}{l}\text { Distal parametrial } \\
\text { invasion/Uretheral } \\
\text { obstruction (N=4) }\end{array}$ & $0 / 40 \%$ & $0 / 40 \%$ & - \\
\hline $\begin{array}{l}\text { Parametrial + } \\
\text { vaginal } \\
\text { invasion/Uretheral } \\
\text { obstruction (N=10) }\end{array}$ & $0 / 100 \%$ & $0 / 80 \%$ & $0 / 20 \%$ \\
\hline Total (N=25) & $4 / 2516 \%$ & $4 / 2317.3 \%$ & $0 / 20 \%$ \\
\hline $\begin{array}{l}\text { Without } \\
\text { retroperitoneal } \\
\text { pelvic invasion } \\
\text { (N=34) }\end{array}$ & $\begin{array}{l}11 / 34 \\
\text { OS }\end{array}$ & & \\
\hline
\end{tabular}

*OS - overall survival

\section{Discussion}

The biological "behaviour" of ovarian cancer is unique and quite different from the classical and well-studied haematogenous dissemination. ${ }^{8}$ Ovarian cancer spreads through the following routes: peritoneal dissemination, direct extension (contact growth), lymphatic and haematogenous pathways. The most common and earliest mode of spread of the epithelial tumours is through exfoliation of cells along the peritoneal surface. ${ }^{9}$ The exfoliated cells migrate directly towards the lesser pelvis and the abdominal peritoneal surface and likely to follow the route of spread of peritoneal fluid from the right paracolic canal towards the right hemidiaphragm. Surface implanted metastases occur in the abdominal cavity and the pelvis. Interesting, but not well-studied, is the fact that these tumours invade the mesothelium, but very rarely they invade the peritoneum deeper. ${ }^{10}$ The vagina is covered by peritoneum in a small part of its upper quarter.

Well-known is that main factor for the successful treatment of advanced ovarian cancer is the maximal cytoreduction. The possibility of its achievement depends on the localization of metastatic disease and their operability. In 2009 FIGO had a revision and direct retroperitoneal pelvic invasion was included as a prognostic factor in the staging of cervical, endometrial and vulvar cancers. The prognostic role of RPI in epithelial ovarian cancer remains unclear. ${ }^{11}$

The results from our study show that invasion in the retroperitoneal structures (excluding lymphatic spread) is not a rare phenomenon in advanced epithelial ovarian cancer - in 42.4 per cent of the patients, and in 16.9 per cent vaginal metastases are observed. Probably the explanation of such high percentages is due to the fact that in 59 patients were performed radical hysterectomy and our pathologists were looking in particular for retroperitoneal invasion. In one study Perreira et al., report 18.9 per cent retroperitoneal involvement unrelated to pelvic lymph nodes and very low 5-year survival of 14.3 per cent for the patients with RPI and early clinical stage (I-IIIB), while 5-year survival reported for the patients without RPI is 50 per cent. ${ }^{11}$ The presence of hematogenous metastases at diagnosis is uncommon and is usually a late finding. Hematogenous metastases in liver and/or lungs are found in only 2 per cent to 3 per cent of the patients when diagnosed with the disease. ${ }^{10}$ In a report by Dauplat et al., distant metastases compliant with stage IV were documented in nearly two-fifths of the patients who died from ovarian cancer initially thought to be confined to the peritoneal cavity. $^{12}$ 


\section{Conclusion}

Vaginal metastasis and distal parametrial invasion towards the pelvic wall in advanced epithelial ovarian cancer seem to be a feature of the more aggressive tumours. Irrespective of the residual tumour size and of the disease stage, patients with vaginal metastases show survival rates similar to those of FIGO stage IV patients. Although the researches in this area should continue we think that it will be felicitous for more aggressive surgical treatment in the early stages of ovarian cancer.

\section{References}

1. Heintz AP, Odicino F, Maisonneuve $P$, et al. Carcinoma of the ovary. FIGO 26th annual report on the results of treatment in gynecological cancer. Int J Gynaecol Obstet. 2006;95:161-192.

2. Jemal A, Siegel R, Xu J, et al. Cancer statistics, 2010. CA Cancer J Clin. 2010;60:277-300.

3. Goodman MT, Howe HL. Descriptive epidemiology of ovarian cancer in the United States, 1992-1997. Cancer. 2003;97(10 Suppl):2615-2630.

4. Engel J, Eckel R, Schubert-Fritschle G, et al. Moderate progress for ovarian cancer in the last 20 years: prolongation of survival, but no improvement in the cure rate. Eur J Cancer 2002;38:2435-45.

5. Jemal A, Bray F, Center, et al. Global cancer statistics. CA Cancer J Clin. 2011;61:69-90.

6. Jemal A, Murray T, Thun M. Cancer Statistics, 2003 53:526. CA Cancer J Clin. 2002;52:23-47.

7. Jemal A, Siegel R, Xu J, et al. Cancer statistics, 2010. CA Cancer J Clin. 2010;60:277Y300.

8. Gupta G, Massague J. Cancer metastasis: building a framework. Cell. 2006;127:679-695.

9. Berek JS, Hacker NF. Practical gynecologie oncology,3rd ed. Philadelphia: Lippincott Williams \& Wilkins, 2000:338

10. Berek JS, Bast RC Jr. Epithelial Ovarian Cancer. In: Kufe DW, Pollock RE, Weichselbaum RR, et al., editors. Holland-Frei Cancer Medicine. 6th edition. Hamilton (ON): BC Decker; 2003. Available from: http://www.ncbi.nlm.nih.gov/books/NBK12433/.

11. Pereira A, Pérez-Medina $T$, Magrina JF, et al. The impact of pelvic retroperitoneal invasion and distant nodal metastases in epithelial ovarian cancer. Surg Oncol. 2014;23(1):40-4.

12. Dauplat J, Hacker NF, Neiberg RK, et al. Distant metastasis in epithelial ovarian carcinoma. Cancer. 1987;60:1561-1566.

\section{PEER REVIEW}

Not commissioned. Externally peer reviewed.

\section{CONFLICTS OF INTEREST}

The authors declare that they have no competing interests.

\section{FUNDING}

None 